\title{
Management of Traumatized Open Apex Teeth with Mineral Trioxide Aggregate Apexification and Demineralized Freeze-dried Bone Allograft as Apical Matrix
}

\author{
${ }^{1}$ Rashmi V Bolli, ${ }^{2}$ MV Sumanthini, ${ }^{3}$ Vanitha U Shenoy, ${ }^{4}$ Aanchal M Agrawal
}

\begin{abstract}
Achievement of a perfect apical seal in the case of a traumatized nonvital open apex tooth is one of the most important factors affecting its long-term success. It can be treated surgically by placing a retrofill or by a nonsurgical approach by apexification. Currently, apexification with mineral trioxide aggregate (MTA) is the treatment of choice in such cases. Herein, due to large apical diameter, limiting the MTA within the canal space is challenging, making it imperative to use a suitable apical matrix. This case report demonstrates successful management of traumatized nonvital open apex teeth with MTA apexification using demineralized freeze-dried bone allograft apical matrix.
\end{abstract}

Keywords: Apexification, Dimineralized freeze-dried bone, Internal matrix, Mineral trioxide aggregate, Open apex.

How to cite this article: Bolli RV, Sumanthini MV, Shenoy VU, Agrawal AM. Management of Traumatized Open Apex Teeth with Mineral Trioxide Aggregate Apexification and Demineralized Freeze-dried Bone Allograft as Apical Matrix. J Contemp Dent 2016;6(3):194-199.

Source of support: Nil

Conflict of interest: None

\section{INTRODUCTION}

Trauma or carious exposure of pulp in developing young permanent teeth may result in pulp necrosis; dentin formation ceases, and root development is arrested, resulting in an open apex. Treatment of teeth with incomplete rhizogenesis presents specific challenges as such teeth have wide open apices, divergent root walls, thin dentinal walls that are susceptible to fracture, larger apical diameter, smaller coronal canal diameter causing difficulty in debridement, and frequent periapical lesion. Loss of a natural constriction at the root apex makes it difficult to control the apical filling extent of root canal

\footnotetext{
${ }^{1,4}$ Postgraduate Student, ${ }^{2}$ Professor, ${ }^{3}$ Professor and Head

${ }^{1-4}$ Department of Conservative Dentistry and Endodontics Mahatma Gandhi Mission's Dental College and Hospital, Navi Mumbai, Maharashtra, India

Corresponding Author: Rashmi V Bolli, Postgraduate Student Department of Conservative Dentistry and Endodontics Mahatma Gandhi Mission's Dental College and Hospital, Navi Mumbai, Maharashtra, India, e-mail: rashmi.bolli@gmail.com
}

filling materials. The size of the wide apical portion of the root canal with thin and fragile dentinal walls makes the root canal rehabilitation a challenging task for the operator. ${ }^{1}$

Due to loss of vitality, apexogenesis will not be a viable option in such cases. The method to induce a calcified barrier in a root with an open apex or the continued apical development of an incomplete root in teeth with necrotic pulp is defined as apexification. ${ }^{2}$ Previously, calcium hydroxide $(\mathrm{CaOH})$ had been the choice for treating open apex cases with apexification technique. However, it has some disadvantages, such as prolonged treatment time, need for multiple visits, reduced fracture resistance of the tooth, and chances of reinfection due to loss of temporary restoration. Hence, single-sitting mineral trioxide aggregate (MTA) apexification has evoked considerable interest. ${ }^{3}$ The MTA is an excellent biocompatible cement developed by Torabinejad and Chivian. ${ }^{3}$ It has shown considerable success as an artificial apical barrier and has become the material of choice for single-visit apexification. ${ }^{4,5}$ In long-term clinical outcome studies of $\mathrm{CaOH}$ and MTA apexification, MTA showed similar healing of periapical lesions in shorter treatment durations. ${ }^{6}$

The internal matrix acts as a layer that forms a barrier for limiting the extension of repair material ${ }^{1}$ such as MTA. This concept was developed by Lemon. Various materials, such as $\mathrm{CaOH}$, hydroxyapatite, resorbable collagen, platelet-rich fibrin (PRF), calcium sulfate, and demineralized freeze-dried bone allograft (DFDBA) are recommended as a matrix material for treating open apex. $^{78}$ The matrix material, DFDBA, is a widely used graft material in procedures of periodontal and oral surgery, ${ }^{6}$ but very few cases are reported where it is used as an apical matrix. The DFDBA is obtained from cortical plate of long bones. As compared with cancellous bone, DFDBA contains higher amount of bone induction proteins and less antigenic potential. ${ }^{9}$ The collagen matrix in DFDBA acts as a scaffold. It provides osteoconductive and osteoinductive behavior to the graft material. ${ }^{10}$

This case report describes the nonsurgical management of traumatized central incisors with wide open apex by MTA apexification in combination with the use of an apical matrix of DFDB allograft. 


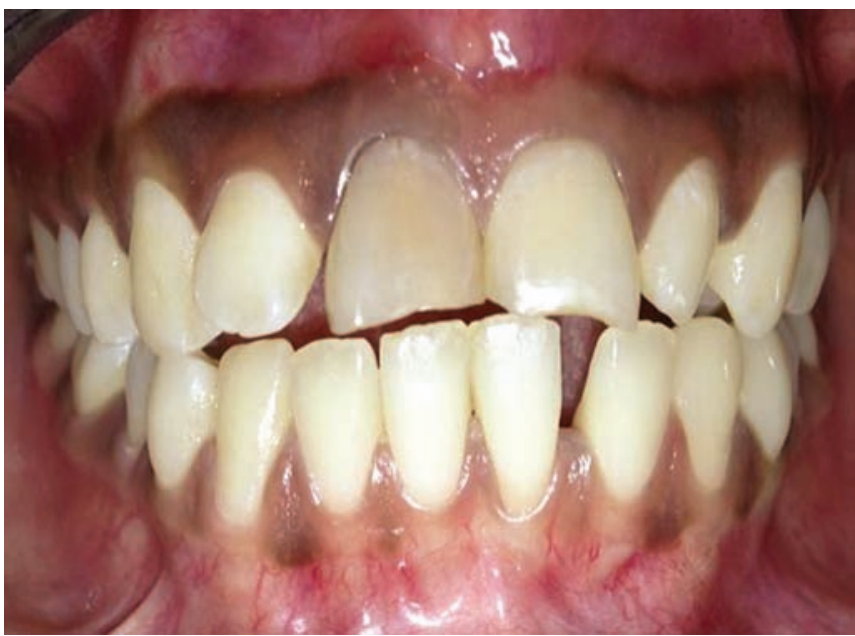

Fig. 1: Preoperative photograph showing discolored maxillary central incisors $(11,21)$

\section{CASE REPORT}

A 19-year-old female patient reported to the Department of Conservative Dentistry and Endodontics, with a chief complaint of pain, occasional bleeding, and mobility in the permanent maxillary right and left central incisors $(11,21)$. Patient gave a history of trauma 8 years earlier, following which patient claimed that she had undergone one sitting of root canal treatment for the same teeth. Patient gave history of anemia for the past 8 years and was not on any medication. Intraoral examination revealed discolored maxillary central incisors (11, 21) (Fig. 1). For 11 and 21, pain on percussion was positive, periodontal probing depths were within normal limits $(<3 \mathrm{~mm})$, and mobility was present. Both 11 and 21 tested negative for electric pulp testing and cold tests. Radiographic examination revealed incompletely formed root apices with apical radiolucency associated with the root apices of 11 and 21 (Fig. 2). A diagnosis of previously initiated root canal treatment with symptomatic apical periodontitis in relation to 11 and 21 was arrived at.

Medical consent from the patient's physician was obtained for performing the root canal treatment. Treatment options given to the patient were nonsurgical endodontic treatment with one-step MTA apexification procedure, endodontic treatment followed by periapical surgery for curettage of the lesion followed by retrofilling, and extraction followed by single-tooth implant or fixed partial denture. Considering the extent of the lesion, age of the patient, medical history of anemia, and surgical trauma that could occur, nonsurgical root canal treatment was decided upon. Both the teeth were isolated with rubber dam, and the endodontic access cavity was modified (Fig. 3). The root canals of 11 and 21 were explored with a \#25 K-file (Mani, Tamil Nadu, India). The canals were patent, wide, and the largest file

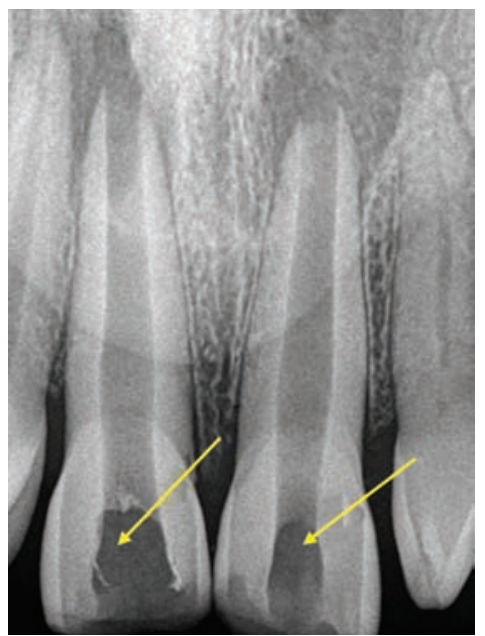

Fig. 2: Preoperative IOPA of 11 and 21 showing previously prepared access cavity

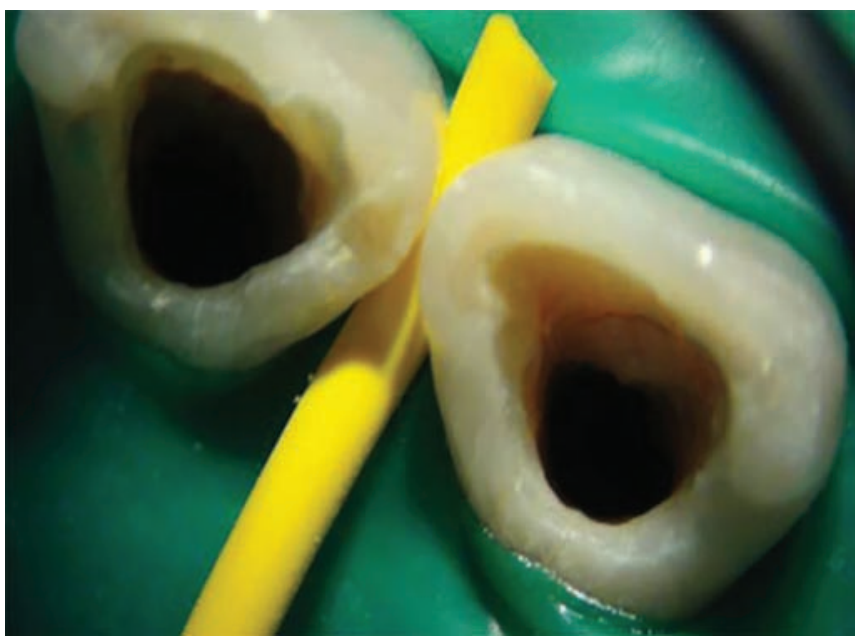

Fig. 3: Dental operating microscope image showing modified access cavity preparation in 11 and 21

to bind to apical extent of both the canals was \#140 K-file (Fig. 4A). An intraoral periapical radiograph (IOPA) was taken to determine the working length (Fig. 4A). The root canals were gently, circumferentially filed with \#120 K-file. The canals were irrigated intermittently with $2.5 \%$ sodium hypochlorite $(\mathrm{NaOCl})$ (Prime Dental Products Pvt. Ltd, Maharashtra, India). Passive ultrasonic irrigation (PUI) was carried out with ultrasonic \#25 K-file (Satellec Acteon Group, New Delhi, India) at a setting of 4 for 1 minute with $\mathrm{NaOCl}$ as irrigant. Final irrigation was done with $0.7 \%$ saline (Fresenius Kabi India Pvt. Ltd, AG Germany). The root canals were then dried with sterile absorbent points (Sure-endo; SureDent Co. Ltd, Gyeonggi-do, Korea). A thick paste of $\mathrm{CaOH}$ (ProDent, Ratnagiri, India) mixed with saline was placed in the root canal (Fig. 4B), and the patient was recalled after 2 weeks. At 2-week recall appointment, her symptoms had resolved. Calcium hydroxide was removed using $\mathrm{H}$-files (Mani, Tamil Nadu, and India) and PUI with \#25 K-file 


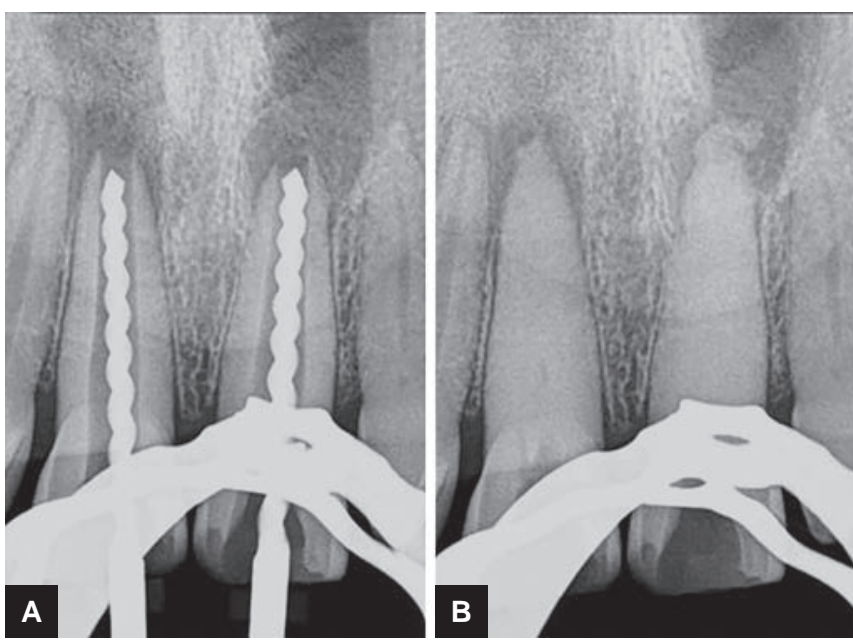

Figs 4A and B: (A) Intraoral periapical showing working length determination in 11 and 21; and (B) dense calcium hydroxide intracanal medicament placed in 11 and 21

(Satellec Acteon Group, New Delhi, India) at a setting of 4 for 1 minute. The root canal was then dried with sterile absorbent points (Dentsply India Pvt Ltd).
It was decided to use DFDBA as an internal matrix at the apical foramen prior to MTA placement. The PRF for apical matrix was not considered for this patient as patient's hemoglobin levels were low $(7.5 \mathrm{mg} / \mathrm{dL})$. The DFDBA (particle size 500-1,040 $\mu \mathrm{m}$, TATA Memorial Hospital Tissue Bank, Parel, Mumbai, India) was mixed with normal saline in a dappen dish to a packable consistency. It was then carried to periapical area under radiographic guidance with the help of endodontic hand pluggers (GDC, Germany stainless steel $\mathrm{CE} \# \mathrm{RCP}$ ) having rubber stop at preadjusted working length (Figs $5 \mathrm{~A}$ and $\mathrm{B}$ ). After having confirmed adequate matrix mass of DFDBA, ProRoot MTA (Dentsply, Ballaigues, Switzerland) was mixed with sterile water as per manufacturer's instructions and placed in the apical third using hand pluggers and compacted with absorbent points (Fig. 6). It was further compacted using indirect ultrasonic condensation. Thus, $5 \mathrm{~mm}$ of apical plug was obtained and a radiograph was taken to confirm the placement of dense MTA plug (Fig. 7). A moistened pellet of cotton was placed in the canal for setting of MTA and access was sealed with Cavit (3M ESPE, Seefeld, Germany).
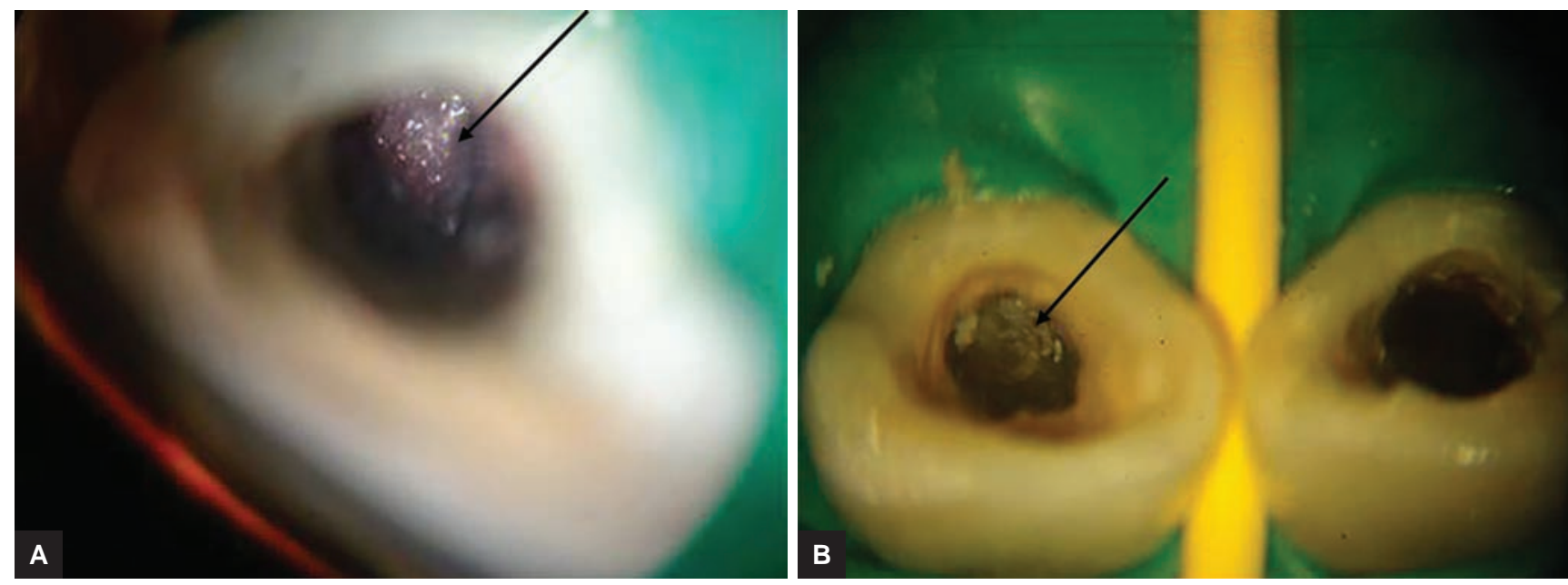

Figs 5A and B: Dental operating microscope image showing DFDBA placed in the apical part of 11 and 21

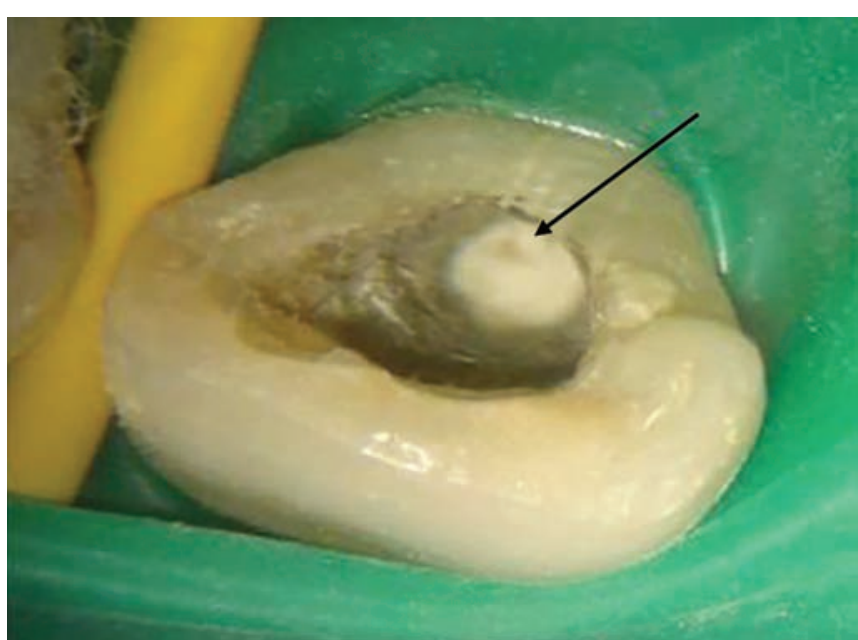

Fig. 6: Dental operating microscope image shows MTA plug of $5 \mathrm{~mm}$ placed in the apical third of the root canals

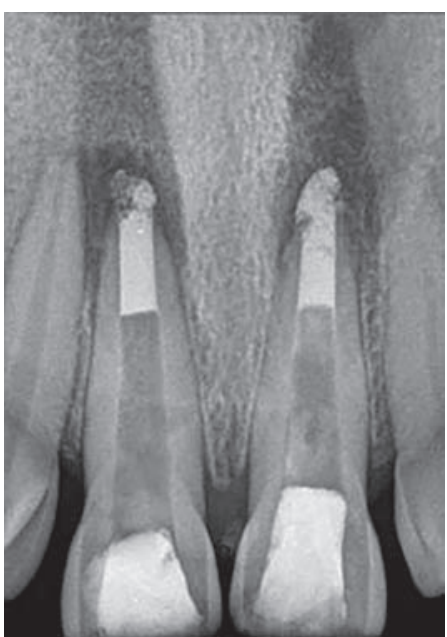

Fig. 7: Intraoral periapical showing $5 \mathrm{~mm}$ MTA plug in 11 and 21 condensed against DFDBA apical matrix 


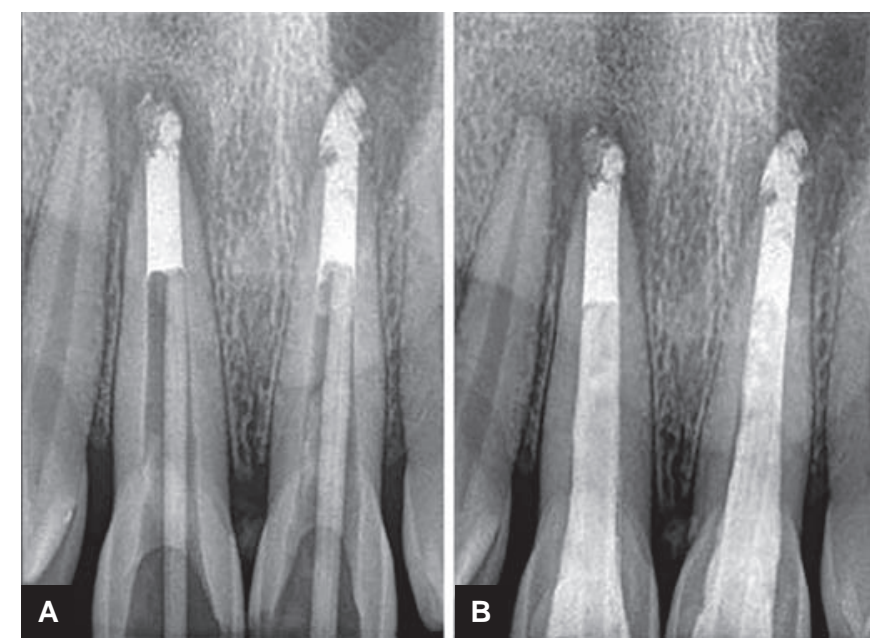

Figs $8 \mathrm{~A}$ and $\mathrm{B}$ : (A) Fiber post selection in 11 and 21; and (B) fiber post cementation done in 11 and 21 with resin cement after 24 hours

Patient was recalled after 24 hours and was asymptomatic. Temporary restoration was removed and the set of MTA was confirmed with an endodontic hand plugger. The root canals were irrigated with $2.5 \% \mathrm{NaOCl}$ followed by saline, dried with paper points, and prefabricated TENAX fiber posts (Coltene Whaledent Pvt. Ltd) (Fig. 8A) for 11 and 21 were cemented using Paracore (Coltene/ Whaldent Inc, Cuyahoga Falls OH, USA) (Fig. 8B). Access cavity was restored with light-cure composite resin (3M ESPE Filtek Z250 XT). Further, the tooth was restored with porcelain fused to metal crown (PFM) (Fig. 9). The patient was recalled at 3 (Fig. 10A), 6, and 9 (Fig. 10B) months. At 9 months of follow-up, the patient was asymptomatic and periapical radiograph demonstrated satisfactory healing. The preoperative and postoperative photographs of the patient are presented in Figures 11A and B, respectively.

\section{DISCUSSION}

Achieving apical seal with the help of an inert root canal filling material is an important factor determining the

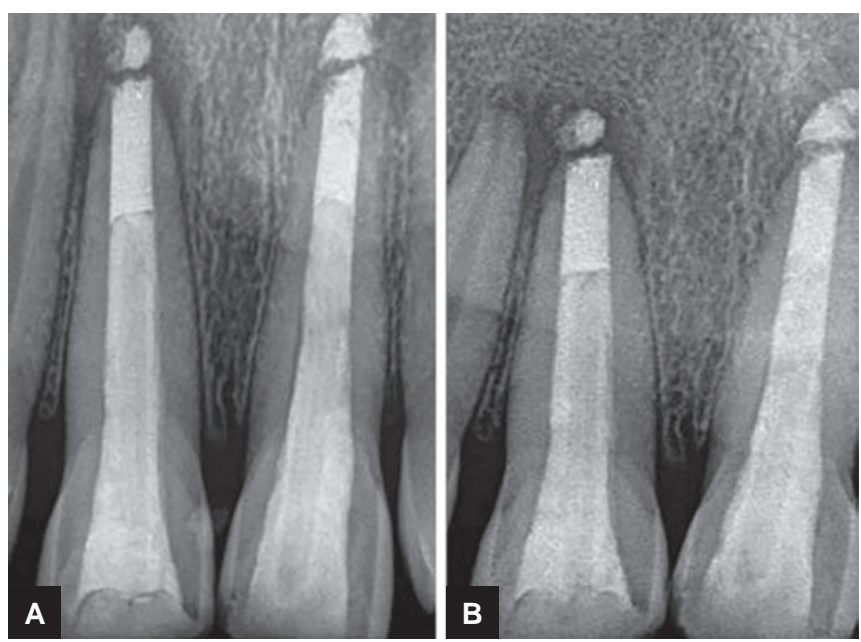

Figs 10A and B: (A) Three months follow-up IOPA radiograph; and (B) 9 months follow-up IOPA radiograph

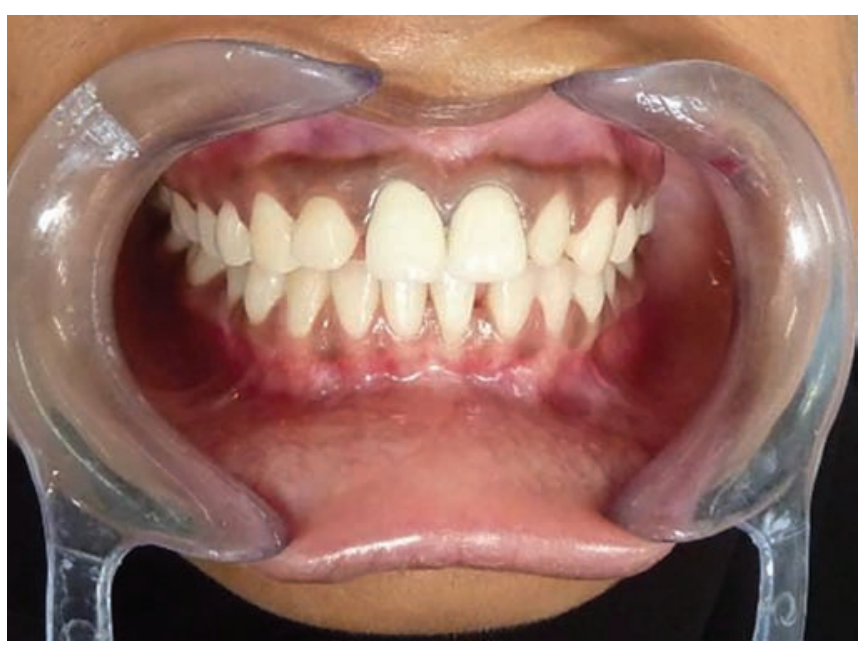

Fig. 9: Postoperative photograph showing PFM crown cemented in 11 and 21

degree of success of the endodontic treatment. Wide open apices, thin and divergent radicular dentin, and enormous necrotic pulp tissue with frequent periapical lesion in nonvital immature anterior teeth pose further complications for their endodontic treatment. The disinfection of root canal space without removing circumferential dentin in such cases is a great challenge, and it relies mainly on chemical disinfection by the action of irrigants and intracanal medicaments. Thus, in such clinical situations, PUI could prove a valuable adjunct. Weller et $\mathrm{al}^{11}$ first described passive ultrasonic agitation technique wherein the efficiency of root canal disinfecting solutions was enhanced by using ultrasonic energy without instrumentation, planing, or contact of the canal walls with an endodontic file or instrument. During PUI, the energy of the formed ultrasonic waves is transmitted from noncutting tip of the agitating instrument to the irrigant that is present in the root canal space. This energy from ultrasonic waves induces acoustic streaming and cavitation in the irrigating solution, ${ }^{12}$ thus obtaining improved disinfection of the root canal space when compared with disinfection technique of root canal by hand instrumentation only. Calcium hydroxide was used as an intracanal medicament during the interappointment period, because the hydroxyl ions that were released in the aqueous environment by the medicament caused antibacterial effects in the root canal system (Siqueira)..$^{13}$ The action lasts as long as a high $\mathrm{pH}$ is maintained. ${ }^{14}$ The antimicrobial activity of $\mathrm{CaOH}$ is related to the lethal effects of hydroxyl ions on bacterial cells by damage to the bacterial cytoplasmic membrane, protein denaturation, and damage to the DNA. ${ }^{14}$

Mineral trioxide aggregate was proposed as a material suitable for one visit apexification, ${ }^{15-18}$ as it combines biocompatibility ${ }^{19}$ and a bacteriostatic action, with favorable sealing ability when used as root-end filling material. The MTA offers a barrier at the apical of the root 

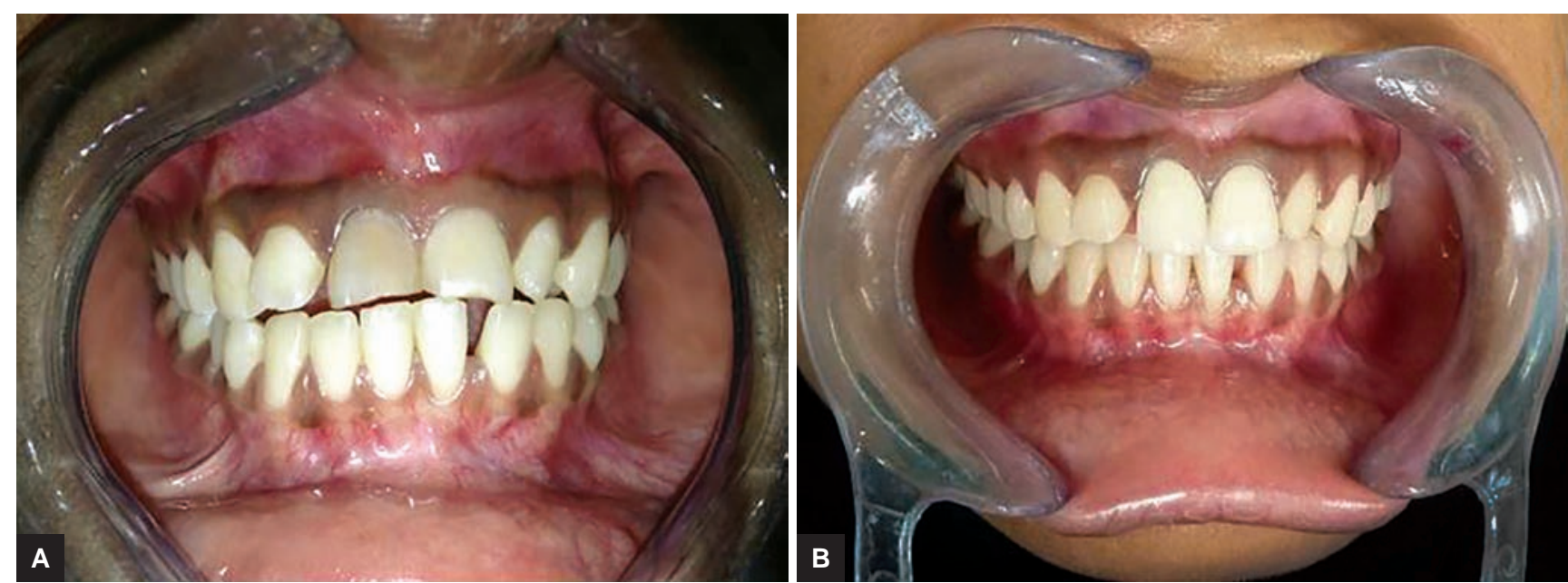

Figs 11A and B: (A) Preoperative photograph of the patient; and (B) postoperative photograph of the patient after ceramometal crown cementation

canal (apical plug) in teeth with necrotic pulps and open apices (Torabinejad and Chivian ${ }^{3}$ ) that permits vertical condensation of warm gutta-percha in the remainder of the canal. According to Parirokh and Torabinejad, ${ }^{20}$ when MTA is placed in direct contact with human tissues, it forms $\mathrm{CaOH}$ that releases calcium ions for cell attachment and proliferation, creates an antibacterial environment by its alkaline $\mathrm{pH}$, modulates cytokine production, and encourages differentiation and migration of hard tissueproducing cells, forming hydroxyapatite on the MTA surface and provides a biologic seal. ${ }^{20}$

In open apex cases, due to large apical diameter (present case \#140), confining MTA within the root canal space is extremely difficult while attempting for voidfree apical plug during hand and indirect ultrasonic condensation. It is important to avoid extrusion of large amount of MTA in the periapical areas as all forms of MTA contain arsenic that may leach out into the periapical tissues. ${ }^{21}$ Although the quantity is insignificant, it can potentially cause toxicity. The extruded large amount of MTA may set before it is disintegrated and resorbed. This might result in persistent inflammatory process that may complicate repair of the periapical tissues. Hence, the internal matrix is placed to prevent MTA extrusion in the periapical region. ${ }^{22,23}$ Various materials are available to be used as an internal matrix, such as PRF and DFDBA. The decision of not using PRF was taken as patient was having consistently low levels of hemoglobin (7.5 mg/dL). Hence, DFDBA was used as an apical matrix. It elicits mesenchymal cell migration, attachment, and osteogenesis when implanted in well-vascularized bone; it induces endochondral bone formation when implanted in tissues that would otherwise not form bone. The DFDBA contains bone morphogenetic proteins (BMPs) such as BMP 2, 4, and 7, which help stimulate osteoinduction. ${ }^{24}$ The BMPs are associated with the organic matrix of bone and embedded within mineral content, so demineralized process in the formation of DFDBA increases its bioavailability. ${ }^{25}$ The BMPs attract mesenchymal stem cells and induce their differentiation into chondrocytes leading to endochondral bone formation. ${ }^{7}$ The BMPs produce multiple effects on bone by acting as mitogens on undifferentiated mesenchymal cells and osteoblast precursors, inducing the expression of the osteoblast phenotype, e.g., increasing alkaline phosphatase activity in bone cells and acting as chemoattractant for mesenchymal cells and monocytes as well as binding to extracellular matrix type IV collagen. ${ }^{26}$

In open apex cases along with wide apical opening, the radicular dentin is thin and fragile; thus, it is important to reinforce the roots, else it would result in root fracture. During the last decade or so, fiber-reinforced posts have gained popularity. The main advantage of fiber post is the uniform distribution of forces in the root, which results in fewer catastrophic failures of tooth structure than that with metal posts, if adequate ferrule is present. Along with its superior esthetics and good mechanical properties, these posts are commonly used in esthetically demanding areas ${ }^{27}$ Hence, fiber post was cemented with dual cure-flowable composite resin cement, which would reinforce the fragile root structure. ${ }^{28}$

\section{CONCLUSION}

Nonvital teeth with immature and wide open apex can be successfully treated nonsurgically with one-step MTA apexification procedure using DFDBA as an apical matrix. Although there are numerous materials that can be used as an apical matrix, the choice of the apical matrix may depend on the cost, ease of availability of matrix material, and patient medical condition. However, further longterm clinical studies are needed to evaluate the clinical outcomes of placing internal apical matrices prior to apexification of teeth with immature apex. 


\section{REFERENCES}

1. Trope M. Treatment of the immature tooth with a non-vital pulp and apical periodontitis. Dent Clin North Am 2010 Apr;54(2):313-324.

2. Bansode P, Ahire C, Pathak S, Dekate K. Apexification of immature teeth using novel apical matrices and MTA barrier: report of two cases. IOSR J Dent Med Sci 2014;13(3):27-31.

3. Torabinejad M, Chivian N. Clinical applications of mineral trioxide aggregate. J Endod 1999 Mar;25(3):197-205.

4. Simon S, Rilliard F, Berdal A, Machtou P. The use of mineral trioxide aggregate in one-visit apexification treatment: a prospective study. Int Endod J 2007 Mar;40(3):186-197.

5. Sumanthini MV, Shah N, Malgaokar M. Management of nonvital maxillary central incisors with open apex using mineral trioxide aggregate apical plugs-case report. J Contemp Dent 2011 Oct-Dec;1(2):40-43.

6. Pradhan DP, Chawla HS, Gauba K, Goyal A. Comparative evaluation of endodontic management of teeth with unformed apices with mineral trioxide aggregate and calcium hydroxide. J Dent Child (Chic) 2006 May-Aug;73(2):79-85.

7. Pawar RB, Margsahayam SV, Shenoy VU, Shaikh SAH. Management of a traumatized open apex tooth with a combination of mineral trioxide aggregate apical plug and platelet-rich fibrin apical matrix. J Contemp Dent 2016;6(1):57-62.

8. Bodhwani M, Shenoy V, Sumanthini MV. Mineral trioxide aggregate apexification in a non vital immature central incisor tooth using an internal matrix. J Contemp Dent 2014 May;4(2): 113-117.

9. Gouldin AG, Fayad S, Mellonig JT. Evaluation of guided tissue regeneration in interproximal defects. (II). Membrane and bone versus membrane alone. J Clin Periodontol 1996 May;23(5):485-491.

10. Grover V,Kapoor A, Malhotra R, Sachdeva S. Bone allografts: a review of safety and efficacy. Indian J Dent Res 2011 May-Jun; 22(3):496.

11. Weller RN, Brady JM, Bernier WE. Efficacy of ultrasonic cleaning. J Endod 1980 Sep;6(9):740-743.

12. Ahmad M, Pitt Ford TR, Crum LA. Ultrasonic debridement of root canals: an insight into the mechanisms involved. J Endod 1987 Mar;13(3):93-101.

13. Andreasen JO, Farik B, Munksgaard EC. Long-term calcium hydroxide as a root canal dressing may increase risk of root fracture. Dent Traumatol 2002 Jun;18(3):134-137.

14. Siqueira JF Jr, Lopes HP. Mechanisms of antimicrobial activity of calcium hydroxide: a critical review. Int Endod J 1999 Sep;32(5):361-369.
15. Koh ET, McDonald F, Pitt Ford TR, Torabinejad M. Cellular response to mineral trioxide aggregate. J Endod 1998 Aug;24(8):543-547.

16. Torabinejad M. Clinical applications of mineral trioxide aggregate. Alpha Omegan 2004 Dec;97(4):23-31.

17. Shabahang $\mathrm{S}$, Torabinejad $\mathrm{M}$. Treatment of teeth with open apices using mineral trioxide aggregate. Pract Periodontics Aesthet Dent 2000 Apr;12(3):315-320.

18. Maroto M, Barbería E, Planells P, Vera V. Treatment of a non-vital immature incisor with mineral trioxide aggregate (MTA). Dent Traumatol 2003 Jun;19(3):165-169.

19. Holland R, de Souza V, Nery MJ, Otoboni Filho JA, Bernabé PF, Dezan Júnior E. Reaction of rat connective tissue to implanted dentin tubes filled with mineral trioxide aggregate or calcium hydroxide. J Endod 1999 Mar;25(3):161-166.

20. Parirokh M, Torabinejad M. Mineral trioxide aggregate: a comprehensive literature review - part III: clinical applications, drawbacks, and mechanism of action. J Endod 2010 Mar;36(3): 400-413.

21. Chang SW, Shon WJ, Lee W, Kum KY, Baek SH, Bae KS. Analysis of heavy metal contents in gray and white MTA and 2 kinds of Portland cement: a preliminary study. Oral Surg Oral Med Oral Pathol Oral Radiol Endod 2010 Apr;109(4): 642-646.

22. Lemon RR. Nonsurgical repair of perforation defects. Internal matrix concept. Dent Clin North Am 1992 Apr;36(2): 439-457.

23. Bargholz C. Perforation repair with mineral trioxide aggregate: a modified matrix concept. Int Endod J 2005 Jan;38(1): 59-69.

24. Shigeyama Y, D'Errico JA, Stone R, Somerman MJ. Commercially-prepared allograft material has biological activity in vitro. J Periodontol 1995 Jun;66(6):478-487.

25. Zenobio EG, Shibli JA. Treatment of endodontic perforations using guided tissue regeneration and demineralized freezedried bone allograft: two case reports with 2-4 year post-surgical evaluations. J Contemp Dent Pract 2004 Aug;5(3):131-141.

26. American Academy Periodontology. Position paper. The potential role of growth and differentiation factors in periodontal regeneration. J Periodontol 1996;67(5):545-553.

27. Gade P, Gade HS, Gade N. A novel technique for intraradicular rehabilitation using MTA, fiber post and composite: a case report. Int J Appl Dent Sci 2016;2(1):17-19.

28. Carvalho CA, Valera MC, Oliveira LD, Camargo CH. Structural resistance in immature teeth using root reinforcements in vitro. Dent Traumatol 2005 Jun;21(3):155-159. 